\title{
A variety of Helicobacter pylori strains colonize the stomach of non-bleeding Egyptian patients with upper gastrointestinal disorders
}

Loaa A. Tag Eldeen ${ }^{1 *}$, Mohamed A. Mohamed ${ }^{2}$, Mohamed M. Awad ${ }^{\wedge}$, Mohamed I. Sheir ${ }^{2}$, Tahany M. Shams ${ }^{3}$ and Mustafa M. Ragheb ${ }^{4}$

\begin{abstract}
Background: Chronic infection with Helicobacter pylori is associated with protean manifestations, which vary from no symptoms to multiple gastric diseases. Other $\mathrm{H}$. pylori infections could provide protection against reflux esophagitis, and lower esophageal cancer. The current study aims to scan H. pylori strains that colonize the stomach of Egyptian patients with upper gastrointestinal disorders and its association with the endoscopic outcomes. Identification of $\mathrm{H}$. pylori strains was done by PCR amplification of the 16s rRNA gene from gastric biopsies, proved to be positive for H. pylori by both Giemsa stain and histopathology. PCR products were purified, sequenced, and aligned to GenBank.

Results: BLAST results of $H$. pylori 16s rRNA gene sequences showed identity between Egyptian $H$. pylori isolates and four H. pylori strain subpopulations: hspSAfrica, hspEAsia, hpEurope, hspWAfrica. The frequency of H. pylori isolates that showed identity to hspEAsia subpopulation was significantly higher in Ulcerative lesions. H. pylori isolates from ulcerative and neoplasm specimens illustrate base substitutions in 16s rRNA gene variable 9 region compared to the consensus sequence of H. pylori 43504 16s rRNA.
\end{abstract}

Conclusion: Different $\mathrm{H}$. pylori strains may be associated with differences in the clinical manifestations and could be used as a prognostic marker to predict the outcome of the H. pylori-associated diseases.

Keywords: Helicobacter pylori, 16s rRNA gene sequence, Upper gastrointestinal disorders, H. pylori Egyptian strain, Endoscopy outcome

\section{Background}

Helicobacter pylori (H. pylori) is a genetically diverse Gram-negative bacteria pathogen that had been identified as group I carcinogen by the International Agency for Research on Cancer (Peter and Beglinger 2007). It chronically infects approximately half of the world population (Malaty 2007). In developing countries, its prevalence could be as high as $90 \%$ compared to below $40 \%$ in developed countries (Tonkic et al. 2012). The prevalence also varies with geographic regions, age,

\footnotetext{
* Correspondence: loaa_tag@hotmail.com

${ }^{1}$ Medical Biochemistry and Molecular Biology Department, Suez Canal

Faculty of Medicine, Ismailia 411522, Egypt

Full list of author information is available at the end of the article
}

socioeconomic status, educational level, living environment, and occupation (Wang and Peura 2011).

Although the majority of infections are asymptomatic, clinical manifestations develop in less than $20 \%$ of those affected (Cover and Blaser 2009). Chronic $H$. pylori infection is associated with variable pathological outcomes, including chronic gastritis, peptic ulcers, atrophic gastritis, intestinal metaplasia, and gastric lymphoma, or cancer development (Ferreira et al. 2008; Kandulski et al. 2008). However, studies suggested that some $H$. pylori infections could protect against illnesses such as esophageal reflux disease, cancer of the cardia and esophagus, asthma, other allergic disease manifestations, inflammatory bowel disease, 
and tuberculosis (Cover and Blaser 2009; Kyburz and Müller 2017).

The variability of the outcome of this chronic infection may be due to differences in the host genetics, environmental factors, and H. pylori genetic diversity. Such diversity, which is geographically and ethnically structured, was found to affect the function, and antigenicity of virulence factors associated with infection (Arents et al. 2009; Falush et al. 2003). H. pylori virulence factors have the ability to modulate its reaction to the host's immune response and thereby adapt to individual host's conditions (Sokic-Milutinovic et al. 2014).

Globally, H.pylori is divided into seven discrete population, hpEurope, hpNEAfrica, hpAfrica1, hpAfrica2, hpAsia2, hpSahul, and hpEastAsia, and subpopulations (hspWafrica and hspSAfrica in hpAfrica1, AE1 and AE2 in hpEurope, hspIndia in hpAsia2, hspEAsia, hspAmerind and hspMaori in hpEastAsia) that are related to geographic localization (Falush et al. 2003).

Differentiation and identification of $H$. pylori strains could be done based on their $16 \mathrm{~s}$ ribosomal RNA (16s rRNA) gene sequence (Banerjee et al. 2011). The 16s rRNA gene is found in all bacteria and comprises nucleotide sequences that are specific to a given bacterial genus (Smith et al. 2004). Molecular tests targeting 16s rRNA gene-of a certain pathogen-are considered specific to confirm infection. As a result, positive amplification of $H$. pylori-specific DNA is thought-out as a direct evidence of its presence (Chong et al. 1996).

The relation between $H$. pylori strains and endoscopic findings was not examined before in Egypt. Therefore, this study aims to examine the association between $H$. pylori strain as dedicated by $16 \mathrm{~s}$ rRNA gene sequences and the endoscopic outcomes in Egyptian patients with upper gastrointestinal disorders.

\section{Patients and methods}

A descriptive study included 50 adult patients from Suez Canal province and Sinai Peninsula presented with dyspeptic symptoms and referred for upper gastroduodenoscopy at the Suez Canal University Hospital. Written informed consent was obtained from all patients after explaining the aims, outcomes, and possible risks of the study. The study protocol conforms to the ethical guidelines of the 1975 Declaration of Helsinki as reflected in a prior approval by the institution's human research committee, and was approved by the Ethics Committee at Suez Canal University. The study was carried out at the gastrointestinal endoscopy unit of Suez Canal University Hospital, Oncology Diagnostic Unit Faculty of Medicine, Suez Canal University, Ismailia, Egypt. Patients were selected according to the following: being more than 18 years, of either sex, no history of recent treatment for $H$. pylori, or proton pump inhibitors. However, patients with a history of gastric surgery, upper gastrointestinal bleeding, or bleeding tendency were excluded.

\section{Endoscopy and histopathology}

In the endoscopy room, patients' age, sex, complaint, and endoscopic examination findings were recorded. Antrum and body gastric biopsies including the epithelium and muscularis mucosa were taken. Slides sectioned from specimens were examined for the presence of $H$. pylori by Giemsa stain, and histopathologically using hematoxylin and eosin stain. The pathologist was blind regarding patients' data and findings.

\section{DNA extraction and PCR amplification of the 16s rRNA gene}

DNA was extracted from $1 \times 3 \mathrm{~mm}$ endoscopic gastric biopsy of 50 pateints, which proved to be $H$. pylori positive by Giemsa stain and histopathologically by hematoxylin and eosin stain, using WizardSV Genomic DNA Purification System (Promega Corporation, Madison, USA). Extracted DNA was quantitated using NanoDrop (ND)1000 Spectrophotometer (NanoDrop Technologies Inc., Washington, USA) and stored in $-20{ }^{\circ} \mathrm{C}$ until used.

PCR was carried out as described previously (Pellicano et al. 2004), using the following primers: F1: 5' ATTAGTGGCGCACGGGTGAGTAA3', R1: 5' TTTAGCATCCCGACTTAAGGC3'; 2nd amplification: F2: 5'GAACCTTACCTAGGCTTGACATTG 3'; R2: 5' TTTAGCATCCCGACTTAAGGC3'; PCR cycling condition: initial denaturation at $94{ }^{\circ} \mathrm{C}$ for $2 \mathrm{~min}, 35$ cycles of denaturation at $94{ }^{\circ} \mathrm{C}$ for $1 \mathrm{~min}$, annealing for $30 \mathrm{~s}$ at $56{ }^{\circ} \mathrm{C}$, extension at $72{ }^{\circ} \mathrm{C}$ for $90 \mathrm{~s}$, and final extension at $72{ }^{\circ} \mathrm{C}$ for $5 \mathrm{~min}$ using Robocycler Gradiant 96 Thermo cycler (STRATAGEN, LA, USA). PCR products were visualized on $2 \%$ ethidium bromide-stained agarose electrophoresed gel.

\section{DNA sequencing and bioinformatics analysis}

PCR products $(480 \mathrm{bp}$ ) were purified (Qiagen, Hilden, Germany) and sequenced as described (Pellicano et al. 2004). The sequencing results were aligned and compared using Basic Local Alignment Search tool "http:// blast.ncbi.nlm.nih.gov/Blast.cgi". Highly similar sequences were retrieved from NCBI and subjected to multiple sequence alignment using the BioEdit software.

\section{Statistical analysis}

Statistical analysis was done using IBM Statistical Package of Social Sciences (SPSS) software version 20.0 for Windows ${ }^{\bullet}$ software. Data was presented as mean \pm standard deviation or percentages. Chi-squared test was used for categorical variables. $P$ value was significant at $<0.05$. 


\section{Results}

H. pylori 16s rDNA by PCR (Fig. 1) was found in the gastric tissue of 47/50 (94\%) patients. Patients' mean age was $42.3 \pm 10.6$ years, $52 \%$ were male, and $53 \%$ lived in rural area. The majority were married (85\%) and 29\% were smokers.

\section{Endoscopic findings and $H$. pylori detection}

Non-ulcerative lesions (NUL; non-erosive gastritis, esophagitis due to acid reflux, and erosive gastroduodenitis) were diagnosed in 21patients, $90 \%$ of specimens were positive for H. pylori DNA. Ulcerative lesions (UL; gastric ulcer, duodenal ulcer, and esophageal ulcer) were diagnosed in 19 patients, whereas $95 \%$ of specimens were positive for $H$. pylori DNA. Neoplastic lesions (NL; adenocarcinoma, adenoma (precancerous), and mucosa-associated lymphoid tissue (MALT) lymphoma) were found in 10 patients, and all were positive for $H$. pylori DNA.

\section{6s rRNA sequencing results}

Sequence analysis of PCR fragments showed that $79 \%$ of sequenced fragments are congruent to 16s rRNA sequences of five bacteria: H. pylori, Gemella species, Gemella haemolysan, Neisseria, and Streptococcus species. The remaining $21 \%$ showed no similarity to any bacterial 16s rRNA sequences at GenBank to date (Table 1, Fig. 2).

\section{6s rRNA sequencing results and endoscopic findings}

The allocation of 16s rRNA gene sequences among endoscopic lesions revealed that $H$. pylori sequences were significantly higher in ulcerative lesions than NUL and NL lesions $[P<0.05]$, whereas $75 \%$ of non-Helicobacter bacteria and $50 \%$ of the undefined sequences were detected in patients with NUL without statistical significant association (Table 1).
$N U L$ non-ulcerative lesions, $U L$ ulcerative lesions, $N L$ neoplastic lesions, NS not significant

\section{Blast results of Egyptian H. pylori 16s rRNA isolates and pathological lesions}

Sequence BLAST of Egyptian H. pylori 16s rRNA gene showed identity to several accessions of $H$. pylori $16 \mathrm{~s}$ rRNA sequences obtained from GenBank (Table 2), whereas, 17/33 (52\%) of the Egyptian H. pylori isolates showed identity to hpAfrical population [hspSAfrica subpopulation (33\%), hspWAfrica subpopulation (18\%)], $12 / 33$ (36\%) H. pylori isolates showed identity to hspEAsia subpopulation, and the least number $4 / 33$ (12\%) showed identity to hpEurope subpopulation.

In ulcerative lesions, the frequency of $H$. pylori isolates that exhibit identity to hspEAsia subpopulation $(47 \%)$ is statistically significantly higher than isolates that show identity to other subpopulations $(P<0.05)$. On the other hand, although the frequencies of $H$. pylori isolates from patients with non-ulcerative lesions that showed identity to hspSAfrica subpopulation (55\%) and isolates from neoplastic lesions that showed identity to hspWAfrica subpopulation $(58 \%)$ were high but with no significant association (Table 3).

\section{Allelic variation among Egyptian $H$. pylori 16s rDNA isolates}

Partial sequences within the variable region V9 and universal U6 region of Egyptian $H$. pylori 16s rDNA isolates were subjected to multiple sequence alignment against 62-base sequences (16s rRNA gene, 1199-1260) that are $100 \%$ homologs among $H$. pylori reference strains; ATCC 43504 and NCTC11637. Based on the nucleotide sequence in $\mathrm{V} 9$, the isolates could be categorized into three alleles. Allele 1 comprises one isolate (from duodenal ulcer) and showed two nucleotide mutations in comparison to $H$. pylori ATCC 43504 and NCTC11637

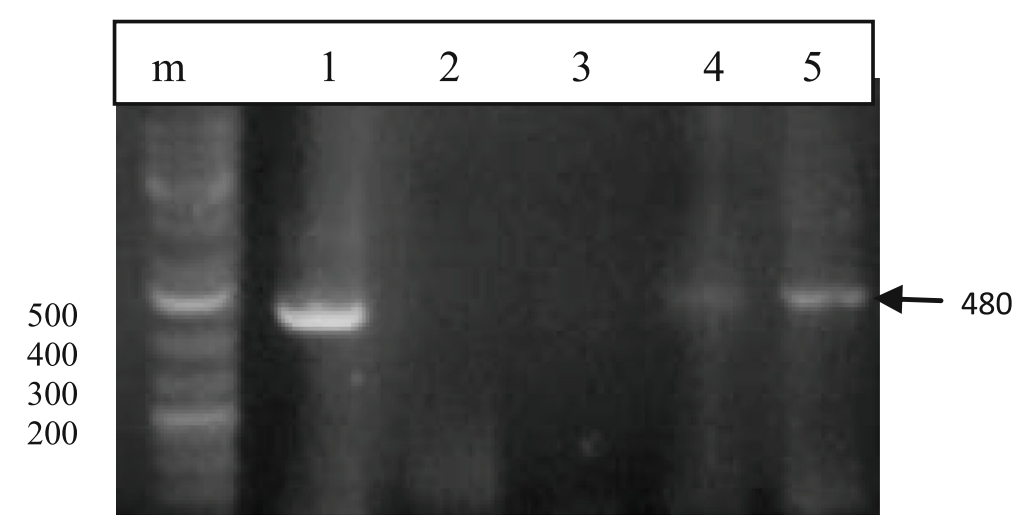

Fig. 1 Two percent agarose gel electrophoresis of PCR products of H. pylori 16s rRNA. Lane M: molecular weight marker (100 bp). Lanes 1, 4, and 5: positive DNA. Lanes 2 and 3: negative DNA samples. Arrow points to expected amplicon band size (480 bp) 
Table 1 Sequence blast of PCR products amplified from gastric biopsies and its distribution among endoscopic lesions of 47 studied patients

\begin{tabular}{|c|c|c|c|c|c|}
\hline Type of 16s rRNA gene sequences & No. (\%) & $\begin{array}{l}\text { NUL } \\
\text { No. (\%) }\end{array}$ & $\begin{array}{l}\text { UL } \\
\text { No. (\%) }\end{array}$ & $\begin{array}{l}\mathrm{NL} \\
\text { No. (\%) }\end{array}$ & $P$ value \\
\hline Undefined sequence (no similarity) & $10(21.2 \%)$ & $5(50 \%)$ & $3(30 \%)$ & $2(20 \%)$ & NS \\
\hline Helicobacter pylori & $33(70.2 \%)$ & $11(33.3 \%)$ & $15(45 \%)$ & $7(21 \%)$ & $0.036^{*}$ \\
\hline \multicolumn{6}{|l|}{ Non-H. pylori organism } \\
\hline Gemella sp. oral clone & $1(2 \%)$ & $1(100 \%)$ & $0(0)$ & $0(0)$ & \\
\hline Gemella haemolysans 25563 strain & $1(2 \%)$ & $0(0)$ & $0(0)$ & $1(100 \%)$ & \\
\hline Neisseria perflava Branham 7078 & $1(2 \%)$ & $1(100 \%)$ & $0(0)$ & $0(0)$ & \\
\hline Streptococcus pneumoniae R6 & $1(2 \%)$ & $1(100 \%)$ & $0(0)$ & $0(0)$ & \\
\hline Total & 47 (100\%) & 19 (40\%) & $18(38 \%)$ & $10(22 \%)$ & \\
\hline
\end{tabular}

*statistically significant

strains (Fig. 3). Allele 2 embraces four isolates (three adenocarcinomas and one gastric ulcer) and illustrates one nucleotide mutation compared to the reference $H$. pylori strains. The third allele includes the rest of isolates and had a sequence identical to that of $H$. pylori ATCC 43504 and NCTC11637 strains (Fig. 3).

\section{Discussion}

$H$. pylori and humans are in intimate relation since the origin of both species in Africa, where three separate $H$. pylori ancestors differentiated: hpAfrica2, hpAfrica1, and hpNEAfrica. hpAfrica2 was a predominant inhabitant in southern Africa, whereas the others were widespread throughout Africa and accompanied human race migration out of Africa and resulted in the emergence of Asian and Oceanic ancestors: hpAsia2, hpAsia, and hpSahul. Subsequent migrations of the African hpNEAfrica and/or the Asian hpAsia2 populations resulted in the appearance of hpEurope population which then became the predominant population of $H$. pylori in Europe, the Middle East, and western Asia (Moodley et al. 2012).

In the present study, the sequence analysis of $H$. pylori 16s rDNA PCR fragments revealed that the H. pylori isolated from Egyptian patients showed identity to four $H$. pylori subpopulations: hspSAfrica, hspWAfrica, hspEAsia, and hpEurope, with predominance of African and Asian strains $(52.5 \%$ and $36 \%$, respectively), which contradict a previous report that assigned $H$. pylori isolated from Egyptians to European H. pylori populations (Linz et al. 2007).

The variety of $H$. pylori populations observed in the current study may be due to the modern Egyptian population which is composed of a majority of ethnic Egyptians; who are a product of, a mixture of ancient Egyptians; multiple invaders from various parts of Asia and Africa; and a minority of multiple ethnicities include the Turks, Greeks, Abases, Nubians, Armenians, Greeks, Italian, and French (http://countrystudies.us/egypt/59. htm, http://countrystudies.us/egypt/59.htm).

The $H$. pylori pathogenicity and the disease outcome are related to its strains, as certain strains are linked to more severe gastric lesions than others. Different strains confer polymorphic genetic loci, including the cag pathogenicity island (cag PAI), the vacA gene, and the $b a b A 2$ gene that seem to be interdependent markers that could reflect the degree of disease risk (Kao et al. 2016).

In the present study, the frequency of $H$. pylori isolates that exhibits identity to East Asia H. pylori strains (hspEAsia subpopulation) is statistically significantly higher in ulcerative lesions than other lesions, confirming a previously published report (Gunaletchumy et al. 2014).

Nearly $100 \%$ of East Asia H. pylori isolates are cagA+ and vacA $s 1$ strains which are linked to peptic ulcer

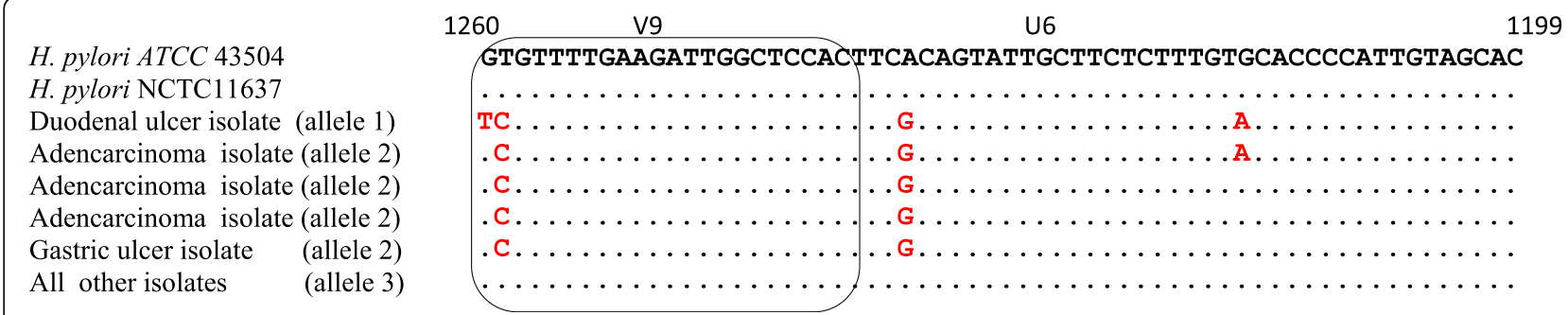

Fig. 2 Chromatograms of gel-purified PCR fragments. a Unidentified sequences with multiple bands and base substitutions. b $\mathrm{H}$. pylori 16rRNA gene sequences 
Table 2 Blast results of Egyptian H. pylori 16s rRNA partial sequence with Gene bank nucleotide consensus sequences

\begin{tabular}{|c|c|c|c|c|}
\hline Endoscopic diagnosis & Strain & No. of patients & Identity & accession number \\
\hline \multirow[t]{6}{*}{ Non-ulcerative lesions (no.11) } & H. pylori SouthAfrica20 & 5 & $97-99 \%$ & CP006691.1 \\
\hline & H. pylori SouthAfrica7 & 1 & $97 \%$ & CP002336.1 \\
\hline & H. pylori oki828 (Japan) & 2 & $99 \%$ & СР006826.1 \\
\hline & H. pylori oki898 (Japan) & 1 & $96 \%$ & СР006826.1 \\
\hline & H. pylori oki128 (Japan) & 1 & $99 \%$ & СР006822.1 \\
\hline & H. pylori strain BM012B (USA) & 1 & $97 \%$ & СР007605.1 \\
\hline \multirow[t]{9}{*}{ Ulcerative lesions (no. 15) } & H. pylori SouthAfrica20 & 2 & $96 \%$ & CP006691.1 \\
\hline & H. pylori SouthAfrica7 & 1 & $97 \%$ & CP002336.1 \\
\hline & H. pylori oki828 (Japan) & 5 & 98-99\% & CP006826.1 \\
\hline & H. pylori oki128 (Japan) & 1 & $99 \%$ & CP006822.1 \\
\hline & H. pylori MKM6 (Japan) & 1 & 98-99\% & AP017362 \\
\hline & H. pylori strain BM012B (USA) & 2 & $97-98 \%$ & СР007605.1 \\
\hline & H. pylori strain BM013B (USA) & 1 & $99 \%$ & СР007606.1 \\
\hline & H. pylori J166 (USA) & 1 & $88 \%$ & СР007603.1 \\
\hline & H. pylori $J 99$ (USA) & 1 & $99 \%$ & СР011330.1 \\
\hline \multirow[t]{4}{*}{ Neoplastic lesions (no. 7) } & H. pylori SouthAfrica20 & 2 & $96 \%$ & CP006691.1 \\
\hline & H. pylori Gambia94/24 (Gambia) & 3 & $88-93 \%$ & СР002332.1 \\
\hline & H. pylori NY40 DNA (Japan) & 1 & $94 \%$ & СР002332. \\
\hline & H.pylori USU-102 (USA) & 1 & $98 \%$ & EU544226 \\
\hline
\end{tabular}

disease (Parsonnet et al. 1997; Lai et al. 2002). H. pylori cag $A+$ strains possess intact cag PAI (pathogenicity-associated island) that encodes antigenic effector protein (CagA), which contains East Asian strains, a tyrosine motif (EPIYA-D) that is highly phosphorylated by Src and Abl family kinases, a process associated with dephosphorylation of host-cell proteins results in impairment of a variety of intracellular signaling systems, morphological changes in gastric epithelium, increase induction of IL-8, and inflammation in human gastric mucosa (Odenbreit et al. 2000; Vilaichone et al. 2004).

VacA (vacuolating cytotoxin) is a pore-forming cytotoxin upon interring host cells; it induces multiple cellular activities, including mitochondria-membrane-channel formation leading to cytochrome $\mathrm{C}$ release and apoptosis. It also binds to cell membrane receptors and initiates a proinflammatory response (Kusters et al. 2006). In addition, VacA in combination with heparan sulfatebinding proteins, released by $H$. pylori, bind host growth factors and may impair mucosal repair, thus contributing to ulcer pathogenesis (Ricci et al. 1996; Ascencio et al. 1995). vacA s1 strains have the highest cytotoxicity because they consistently induce cell vacuolation and are associated with high levels of inflammation in the gastric mucosa (Miftahussurur and Yamaoka 2015).

In the current study, more than half of the H. pylori isolates from neoplastic lesions exhibit identity to hspWAfrica (Gambia94/24, USU-102) and hspEAsia (Japan strains) subpopulations; west Africa and Japan are among the highest incidence of gastric cancer in Africa and East Asia (20.3/100000 and 31.1/100000 people, respectively) (Asombang et al. 2014; Lin et al. 2011).

hspWAfrica and hspEAsia are $c a g A^{+}$strains (Bullock et al. 2017), a virulence factor that is directly related to gastric cancer development by several studies (Matos et al. 2013; Hatakeyama 2014). Intracellulary, the phosphorylated CagA binds to the phosphatase SHP-2 and affects the adhesion, spreading, proliferation, and

Table 3 Relation between H. pylori subpopulations and endoscopic diagnosis of the studied patients (no. 33)

\begin{tabular}{|c|c|c|c|c|c|}
\hline Endoscopic diagnosis & $\begin{array}{l}\text { hspSAfrica (SouthAfrica20, } \\
\text { SouthAfrica7)* }\end{array}$ & $\begin{array}{l}\text { hspWAfrica (Gambia94/24, } \\
\text { J166, J99, USU-102)* }\end{array}$ & $\begin{array}{l}\text { hspEAsia (oki828, oki898, } \\
\text { oki128) }\end{array}$ & $\begin{array}{l}\text { hpEurope (BM012B, } \\
\text { BM013B)* }\end{array}$ & $P$ value \\
\hline Non-ulcerative lesions & $6 / 11(55 \%)$ & $0 / 11(0 \%)$ & $4 / 11(36 \%)$ & $1 / 11(9 \%)$ & NS \\
\hline Ulcerative lesions & $3 / 15(20 \%)$ & 2/15 (13\%) & $7 / 15(47 \%)$ & $3 / 15(20 \%)$ & 0.046 \\
\hline Neoplastic lesions & $2 / 7(28 \%)$ & 4/7 (58\%) & $1 / 7$ (14\%) & 0/7 (0\%) & NS \\
\hline
\end{tabular}

NS not significant

*[31, 45, E1] 


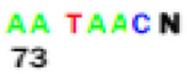

A

Fig. 3 Partial sequence alignment of the 16 s rDNA variable V9 and universal U6 regions of H. pylori isolates from Egyptian patients that are $100 \%$ homologous among H. pylori ATCC 43504 and H. pylori NCTC11637 reference strains. Dots indicate the identity with the reference strains and letters indicate the base substitution. Isolates specify three individual 16S rDNA V9 alleles (signature sequences) at positions 1239-1260 (Escherichia coli nomenclature (DSRG (DNA Sequencing Research Group) n.d.))

migration of the host cell (Yamazaki et al. 2003; Boonyanugomol et al. 2011). Furthermore, dephosphorylated CagA affects Akt signaling pathway which in turn activates NF- $\mathrm{KB}$ and $\beta$-catenin and, as a result, contributes to cellular proliferation and inflammation (Suzuki et al. 2009).

It should be noted, in the present study, nonulcerative lesions exhibit a high prevalence of $H$. pylori isolates that show identity to the hspSAfrica subpopulation. The relation of humans of African origin infected with African strains under hspSAfrica subpopulation to the less invasive gastric disease is documented before, referred to as "the African enigma" as though a high percentage of populations carry $H$. pylori, but the rate of gastric ulcer and cancer is rather low, raising the possibility that African strains of $\mathrm{H}$. pylori may have reduced virulence due to convolution of both species over a prolonged period of time. Disparity among the geographic ancestry of human hosts and the geographic origin of $H$. pylori strains has been associated with more severe gastric pathology and the development of premalignant gastric lesions (de Martel et al. 2013).

Sequence variation in the $H$. pylori $16 \mathrm{~S}$ rDNA variable regions occurs, providing a reliable system for sub-typing (Monstein et al. 2001). In the present study, sequence analysis of $16 \mathrm{~s}$ rRNA gene V9 revealed that one $H$.pylori isolate from duodenal ulcer lesion showed two nucleotide mutations in comparison to H. pylori ATCC 43504 and NCTC11637 reference strains. In addition, four isolates showed one nucleotide mutation compared to the reference strains. H. pylori allelic diversity is probably due to mutations, interspecies genetic recombination, and long evolutional history of the species (Suerbaum and Josenhans 2007).
It is worth noting that the nucleotide sequence of ten PCR fragments could not be aligned to any gene bank sequence. Chromatograms of these gel-purified PCR fragments show it properly has multiple different DNA bands of the same size, exhibiting multiple base substitutions (Fig. 2) (DSRG (DNA Sequencing Research Group) n.d.). Considering, in this study, the multiple bands were amplified from histological positive $H$. pylori specimens, it could be presumed that these PCR fragments belonged to different $H$. pylori strains colonizing the gastric mucosa of the same patients. In support of this conclusion, Israel et al. reported that a single host can carry several $H$. pylori strains, which can change over time owing to endogenous mutations or chromosomal recombination and rearrangement between them (Israel et al. 2001).

Unexpectedly, four 16s rRNA PCR fragments amplified from histologically positive $H$. pylori specimens show similarity to non-Helicobacter species, which is Gemella species, Gemella haemolysan, Neisseria, and Streptococcus species. Most of this non-Helicobacter species were upper respiratory tract microflora and capable of colonizing the stomach of $H$. pylori-positive patients; upper gastrointestinal disorders associated with low acid level induced by H. pylori may enable non-Helicobacter bacteria to survive and colonize in the human stomach (Husebye 2005; Yuan et al. 2012).

The reason why these organisms were amplified may be due to the discovery that, although their 16s rRNA gene sequences showed less than $80 \%$ identity to $16 \mathrm{~s}$ rRNA gene sequences of $H$. pylori 43504 strain, the forward primer used in the second amplification and sequencing is $90 \%$ matched to nucleotides in 16s rRNA gene of these organisms (especially the three 3'nts of the primer are $100 \%$ matched). 
In this study, non-Helicobacter bacteria colonize patients with NUL and neoplastic lesions. The co-existence of non-Helicobacter bacterias with $H$. pylori infection may influence the pathogenesis of stomach disorders. Non- $H$. pylori bacteria and/or their byproducts may act as a persistent antigenic stimulus that augments the inflammatory response induced by $H$. pylori infection, thus eliciting a more vigorous inflammatory response and leading to the development of atrophic corpus gastritis (Sanduleanu et al. 2001).

\section{Conclusion}

The pathology of $H$. pylori-associated diseases depends on the strain and subpopulation of the bacteria. Sequencing and analysis of the 16rRNA gene PCR product data could be a useful diagnostic and prognostic tool of the pathogen outcome. Further studies are needed to confirm these results and to exploring synergistic effects of non-H. pylori bacteria on $H$. pylori infection for gastrointestinal diseases.

\section{Abbreviations}

16s rRNA: 16s ribosomal RNA; H. pylori: Helicobacter pylori; NL: Neoplastic lesions; NS: Not significant; NUL: Non-ulcerative lesions; PCR: Polymerase chain reaction; UL: Ulcerative lesions

\section{Acknowledgments}

The authors thank the members of oncology diagnostic unit, Faculty of Medicine, Suez Canal University.

\section{Authors' contributions}

LT contributed to the study design, processing of tissue, and nucleic acid extraction and amplification; analyzed and interpreted the patient data regarding sequencing results and blast analysis; and is a major contributor in writing the manuscript. MF contributed to the endoscopy-guided tissue collection and collection and statistical analysis of patient data; interpreted the data; and is a minor contributor in writing the manuscript. MR contributed in the study design and is a major contributor in writing the manuscript. TS performed the histological examination of the gastric tissues. MM and MS contributed to the study design and overall supervision of the study. All authors read and approved the final manuscript.

\section{Funding}

The research was funded by the researchers

\section{Availability of data and materials}

All relevant data are included within the paper. Raw data are available from the corresponding author for researchers who meet the criteria for access to confidential data.

\section{Ethics approval and consent to participate}

The study was approved by the Faculty of Medicine ethical committee, Suez Canal University. A written informed consent was obtained from the participants

\section{Consent for publication}

Not applicable

\section{Competing interests}

The authors declare that they have no competing interests.

\section{Author details}

${ }^{1}$ Medical Biochemistry and Molecular Biology Department, Suez Canal Faculty of Medicine, Ismailia 411522, Egypt. ' Internal Medicine Department, Suez Canal Faculty of Medicine, Ismailia 411522, Egypt. ${ }^{3}$ Pathology
Department, Suez Canal Faculty of Medicine, Ismailia 411522, Egypt. ${ }^{4}$ Infectious Diseases Department, Suez Canal Faculty of Medicine, Ismailia 411522, Egypt.

Received: 27 February 2019 Accepted: 31 October 2019

Published online: 11 December 2019

\section{References}

Arents NL, van Zwet AA, Thijs JC, Kooistra-Smid AM, van Slochteren KR, Degener JE (2009) The importance of vacA, cagA, and iceA genotypes of Helicobacter pylori infection in peptic ulcer disease and gastroesophageal reflux disease. Am J Gastroenterol 6:2603-2608

Ascencio F, Hansson HA, Larm O, Wadstrom T (1995) Helicobacter pylori interacts with heparin and heparin-dependent growth factors. FEMS Immunol Med Microbiol 12(3-4):265-272

Asombang AW, Rahman R, Ibdah JA (2014) Gastric cancer in Africa: current management and outcomes. World J Gastroenterol 20(14):3875-3879

Banerjee H, Gramby M, Hawkins Z (2011) Molecular Diagnosis of Helicobacter pylori strain by $16 \mathrm{~S}$ rDNA PCR amplification and direct sequencing. J Bioprocess Biotech 1:3

Boonyanugomol W, Chomvarin C, Baik SC, Song JY, Hahnvajanawong C, Kim KM et al (2011) Role of cagA-positive Helicobacter pylori on cell proliferation, apoptosis, and inflammation in biliary cells. Dig Dis Sci 56:1682e92

Bullock KK, Shaffer CL, Brooks AW, Secka O, Forsyth MH, McClain MS (2017) Genetic signatures for Helicobacter pylori strains of West African origin. PLoS ONE 12(11):e0188804

Chong SK, Lou Q, Fitzgerald JF, Lee CH (1996) Evaluation of 16SR RNA gene PCR with primers $\mathrm{Hp} 1$ and $\mathrm{Hp} 2$ for detection of Helicobacter pylori. J Clin Microbiol 34:2728-2730

Cover TL, Blaser MJ (2009) Helicobacter pylori in health and disease. Gastroenterology. 136:1863-1873

de Martel C, Forman D, Plummer M (2013) Gastric cancer: epidemiology and risk factors. Gastroenterol Clin N Am 42:219-240

DSRG (DNA Sequencing Research Group) Troubleshooting Resource Web page. http://www.abrf.org/index.cfm/stwr.home.

Falush D, Wirth T, Linz B, Pritchard JK, Stephens M, Wang X (2003) Traces of human migrations in Helicobacter pylori populations. Science. 299:1582-1585

Ferreira AC, Isomoto H, Moriyama M, Fujioka T, Machado JC, Yamaoka Y (2008) Helicobacter and gastric malignancies. Helicobacter 13:28-34

Gunaletchumy SP, Seevasant I, Tan MH, Croft AJ, Mitchell HM, Goh KL et al (2014) Helicobacter pylori genetic diversity and gastro-duodenal diseases in Malaysia. Sci Rep 4:7431

Hatakeyama M (2014) Helicobacter pylori CagA and gastric cancer: a paradigm for hit-and-run carcinogenesis. Cell Host Microbe 15:306-316

Husebye E (2005) The pathogenesis of gastrointestinal bacterial overgrowth. Chemotherapy. 51(Suppl 1):1-22

Israel DA, Salama N, Krishna U, Rieger UM, Atherton JC, Falkow S, Peek RM (2001) Helicobacter pylori genetic diversity within the gastric niche of a single human host. Proc Natl Acad Sci U S A 98(25):14625-14630

Kandulski A, Selgrad M, Malfertheiner P (2008) Helicobacter pylori infection: a clinical overview. Dig Liver Dis 40:619-626

Kao CY, Sheu BS, Wu JJ (2016) Helicobacter pylori infection: an overview of bacterial virulence factors and pathogenesis. Biom J 39(1):14-23

Kusters JG, van Vliet AH, Kuipers EJ (2006) Pathogenesis of Helicobacter pylori infection. Clin Microbiol Rev 19(3):449-490

Kyburz A, Müller A (2017) Helicobacter pylori and Extragastric Diseases. In: Tegtmeyer N, Backert S (eds) Molecular pathogenesis and signal transduction by helicobacter pylori. Springer International Publishing: Springer, pp 325-347

Lai CH, Kuo CH, Chen YC, Chao FY, Poon SK, Chang CS, Wang WC (2002) High prevalence of cagA_ and babA2-positive Helicobacter pylori clinical isolates in Taiwan. J Clin Microbiol 40:3860-3862

Lin Y, Ueda J, Kikuchi S et al (2011) Comparative epidemiology of gastric cancer between Japan and China. World J Gastroenterol 17(39):4421-4428

Linz B, François B, Yoshan M, Andrea M, Hua L, Roumagnac P, Falush D, et al. Supplementary information on H. pylori simulations 2007. https:// www.ncbi.nlm.nih.gov > NCBI > Literature > PubMed Central (PMC). Accessed 7 Feb 2007.

Malaty HM (2007) Epidemiology of Helicobacter pylori infection. Best Pract Res Clin Gastroenterol 21:205-214 
Matos Jl, de Sousa HA, Marcos-Pinto R, Dinis-Ribeiro M (2013) Helicobacter pylori CagA and VacA genotypes and gastric phenotype: a meta-analysis. Eur J Gastroenterol Hepatol 25:1431-1441

Miftahussurur M, Yamaoka Y (2015) Helicobacter pylori virulence genes and host genetic polymorphisms as risk factors for peptic ulcer disease. Expert Rev Gastroenterol Hepatol 9(12):1535-1547

Monstein HJ, Shohreh Nikpour-Badr A, Jon Jonasson HJ (2001) Rapid molecular identification and subtyping of Helicobacter pylori by pyrosequencing of the 16S rDNA variable V1 and V3 regions. FEMS Microbiol Lett 199:103-107

Moodley Y, Linz B, Bond RP, Nieuwoudt M, Soodyall H, Schlebusch CM, Bernhöft $S$ et al (2012) Age of the association between Helicobacter pylori and man. PLoS Pathog 8(5):e1002693

Odenbreit S, Püls J, Sedlmaier B, Gerland E, Fischer W, Haas R (2000) Translocation of Helicobacter pylori CagA into gastric epithelial cells by type IV secretion. Science 287:1497-1500

Parsonnet J, Friedman GD, Orentreich N, Vogelman H (1997) Risk for gastric cancer in people with CagA+ or CagA-Helicobacter pylori infection. Gut. 40: 297-301

Pellicano R, Mazzaferro V, Grigioni WF, Cutufia MG, Fagoonee S, Silengo L, Rizzetto M et al (2004) Helicobacter species sequences in liver samples from patients with and without hepatocellular carcinoma. World J Gastroenterol 10(4):598-601

Peter S, Beglinger C (2007) Helicobacter pylori and gastric cancer: the causal relationship. Digestion. 75(1):25-35

Ricci V, Ciacci C, Zarrilli R et al (1996) Effect of Helicobacter pylori on gastric epithelial cell migration and proliferation in vitro: role of VacA and CagA. Infect Immun 64(7):2829-2833

Sanduleanu S, Jonkers D, De Bruïne A (2001) Double gastric infection with Helicobacter pylori and non-Helicobacter pylori bacteria during acidsuppressive therapy: increase of pro-inflammatory cytokines and development of atrophic gastritis. Aliment Pharmacol Ther 15:1163-1175

Smith SI, Oyedeji KS, Arigbabu AO, Cantet F, Megraud F (2004) Comparison of three PCR methods for detection of Helicobacter pylori DNA and detection of cagA gene in gastric biopsy specimens. World J Gastroenterol 10:1958-1960

Sokic-Milutinovic A, Popovic D, Alempijevic T, Dragasevic S, Lukic S, PavlovicMarkovic A (2014) Helicobacter pylori infection and gastric cancer — is eradication enough to prevent gastric cancer. In: Roesler B (ed) Trends in Helicobacter pylori infection. In Tech, Rijeka, pp 155-173

Suerbaum S, Josenhans C (2007) Helicobacter pylori evolution and phenotypic diversification in a changing host. Nat Rev Microbiol 5:441-452

Suzuki M, Mimuro H, Kiga K, Fukumatsu M, Ishijima N, Morikawa H et al (2009) Helicobacter pylori CagA phosphorylation independent function in epithelial proliferation and inflammation. Cell Host Microbe 5:23e34

Tonkic A, Tonkic M, Lehours P, Mégraud F (2012) Epidemiology and diagnosis of Helicobacter pylori infection. Helicobacter. 17(Suppl 1):1-8

Vilaichone RK, Mahachai V, Tumwasorn S, Wu JY, Graham DY, Yamaoka Y (2004) Molecular epidemiology and outcome of Helicobacter pylori infection in Thailand: a cultural cross roads. Helicobacter. 9(5):453-459

Wang AY, Peura DA (2011) The prevalence and incidence of Helicobacter pylori associated peptic ulcer disease and upper gastrointestinal bleeding throughout the world. Gastrointest Endosc Clin N Am 21:613-635

Yamazaki S, Yamakawa A, Ito Y, Ohtani M, Higashi H, Hatakeyama M et al (2003) The CagA protein of Helicobacter pylori is translocated into epithelial cells and binds to SHP-2 in human gastric mucosa. J Infect Dis 187:334e7

Yuan H, Li-Hua H, Di X (2012) Bacterial flora concurrent with Helicobacter pylori in the stomach of patients with upper gastrointestinal diseases. World J Gastroenterol 18(11):1257-1261

\section{Publisher's Note}

Springer Nature remains neutral with regard to jurisdictional claims in published maps and institutional affiliations.

\section{Submit your manuscript to a SpringerOpen ${ }^{\circ}$ journal and benefit from:}

- Convenient online submission

- Rigorous peer review

- Open access: articles freely available online

High visibility within the field

Retaining the copyright to your article

Submit your next manuscript at $\boldsymbol{\nabla}$ springeropen.com 